Sussman, M. (1955). J. gen. Microbiol. 13, 295-309

\title{
'Fruity' and other Mutants of the Cellular Slime Mould, Dictyostelium discoideum: a Study of Developmental Aberrations
}

\author{
By M. SUSSMAN \\ Northwestern University, Evanston, Illinois, U.S.A.
}

SUMMARY: Study of three mutants of Dictyostelium discoideum-Fruity, Bushy and Dwarf--provide specific examples of aberrant behaviour during aggregation and the construction of fruiting bodies. The proportion of initiator cells in the population and the optimal population density for aggregation have been shown to be under genetic control. In the Fruity mutant, the great increase in the number of initiator cells leads to the formation of aggregates composed of very few individuals and correspondingly tiny fruits. The morphology of the aggregates and fruits and the regulatory properties of this morphogenetic system have been examined.

Slime mould myxamoebae, otherwise typical Protista, collectively display a remarkable developmental capacity leading to the formation of organized multicellular structures (Raper, 1941; Bonner, 1944; Sussman, 1955). Aggregation, the part of the morphogenetic sequence which is of chief concern here, serves as a device to bring the hitherto independent cells into a compact mass. It begins after the stationary growth phase has been reached, the myxamoebae lengthening greatly and orienting radially. The cells then move in toward centres of aggregation, at first as individuals and later in ramified cell streams. The conical aggregate which results is transformed into an organized pseudoplasmodium which migrates over the agar surface and ultimately gives rise to a sessile fruiting body consisting of a spore mass, a parenchymatous stalk, and a basal disk.

Some insight into the mechanisms underlying the aggregative process has been gained as a result of previous investigations. The response of the outlying cells to the aggregative stimulus has been shown by a variety of means to be chemotactic (Runyon, 1942; Bonner, 1947, 1949; Shaffer, 1953; Sussman \& Lee, 1954, 1955). The attracting substances, given the generic name 'acrasin' by Bonner, are produced at the aggregative centres and along the streams and are readily diffusible and highly unstable. That both the agents and the chemotactic responses are specific has been indicated in studies of mixed aggregations by cells of different species and genera (Raper \& Thom, 1941) and by treatment of myxamoebae with washings obtained from heterologous aggregates and pseudoplasmodia (Shaffer, 1953).

The aggregation of myxamoebae on a washed agar distilled water substratum has been examined under conditions where the cells remained constant in number and where rigorous control over population size and density could be achieved (Sussman \& Noel 1952; Sussman, 1952).

The population density (no. cells $/ \mathrm{mm}^{2}$ ) radically influenced the number of 
aggregative centres appearing within populations of constant size. The population density which permitted maximal centre formation was found to be characteristic of the species employed (Sussman \& Noel, 1952) and largely invariant, but it could be altered by addition to the washed agar medium of a restricted number of substances, notably including the amino acid histidine and the purine base adenine (Bradley \& Sussman, 1954).

At the optimal population density, the number of centres was directly proportional to the number of cells present. Two independent experimental approaches (Sussman \& Noel, 1952; Sussman, 1952) indicated that this proportionality stems from the fact that the evocation of each centre requires the presence of a special initiator cell and that, under the conditions employed, only a few cells in the population are so constituted. In the species Dictyostelium discoideum used in the current studies, the ratio of initiator cells to responder cells was found to be $1: 2200$.

Heritable modifications of the aggregative pattern have previously been observed (Sussman \& Sussman, 1953; Sussman, 1954) in aggregateless mutants which remain as dispersed amoebae and in some fruitless varieties which can start aggregating but which cannot complete the process. The present paper deals with the aberrant behaviour of three other mutant stocks, both during aggregation and in the subsequent erection of fruiting structures. In contrast to the morphogenetically deficient mutants alluded to above, all three strains can aggregate and produce fruiting structures with viable spores. They are of particular interest in that the modifications of their aggregative patterns include changes in the optimal population density for centre formation and/or increases in the proportion of initiator cells.

\section{METHODS}

Organisms and methods of culture. Dictyostelium discoideum (Raper) strain $\mathrm{NC}-4$, including the wild type and three mutants was used in this investigation. The stocks were grown routinely on SM agar (Sussman, 1951) in association with Aerobacter aerogenes. For routine transfers 4 or 5 spore masses were picked and spread with a few drops of $48 \mathrm{hr}$. A. aerogenes broth culture. For clonal platings, less than 200 spores were inoculated, each viable spore giving rise to a plaque (Sussman, 1951) after 3 days of incubation at $22^{\circ}$.

Washed agar medium for aggregation experiments. Twenty-five g. of Difco Bacto agar was washed on a table-top Büchner filter with 6 l. distilled water and dissolved in 11 . water; this will be referred to as ' minimal agar'. In certain experiments streptomycin sulphate ( 370 units/l.) was added before pouring the plates. Streptomycin has been found (unpublished data) to aid in preventing the growth of bacteria and therefore of the myxamoebae without interfering with the developmental pattern.

Preparation of the cells and experimental procedures. The organisms were grown for about $44 \mathrm{hr}$., by which time the stationary growth phase had been reached but aggregation had not yet begun. The cells were harvested with chilled water and spun at 1000 r.p.m. for 5 min. in an International refrigerated 
centrifuge to remove the few remaining bacteria. After three more washings the myxamoebae were suspended in salt solution (Bonner, 1947) and counted in a haemocytometer. Dilutions of the suspension were dispensed in various sized drops on minimal agar with $0.1 \mathrm{ml}$. Mohr pipettes. The Petri dish covers were left open until the fluid had been absorbed by the agar, after which the plates were incubated at $\mathbf{2 2}^{\circ}$. Counts of aggregative centres and fruits were made by microscopic examination after 18 and $36 \mathrm{hr}$. of incubation.

\section{RESULTS}

\section{Isolation and characterization of the Fruity mutant of Dictyostelium discoideum}

This stock, as well as the mutants described later, was encountered after ultraviolet irradiation of the wild type. The procedure used was described elsewhere (Sussman \& Sussman, 1953). The mutant was recognized by its ability to produce relatively enormous numbers of tiny fruiting bodies, which property suggested the designation Fruity and the abbreviated symbol, Fty-1. The Fruity mutant differs from the wild type in certain other respects. While the growth rates are approximately equal, the mutant plaques are much smaller than those of the wild type and possess a sharper and more regular periphery. Moreover, the first fruitings of the mutant appear when the plaques are very tiny, whereas in the wild type fruiting is considerably more delayed. The mutant phenotype is very stable and no reversions have as yet been detected in the course of hundreds of clonal and mass cultivations. The spores and vegetative myxamoebae of the mutant are indistinguishable from those of the wild type by cursory microscopic observation. Detailed cytological comparisons have not been made.

\section{Fty-1 aggregations on minimal agar}

Fty-1 was grown and prepared for experiment as described in the Methods section. Myxamoebae suspensions were dispensed on minimal agar in volumes ranging from 0.005 to $0.1 \mathrm{ml}$. The specific dilutions were chosen in order that a constant number of cells be delivered in each sample. Previous experiments (Sussman \& Noel, 1952) had shown that the area covered by the drops and, thereby, the population density of the cells, are functions of the volume delivered. In each experiment, the population densities were checked either by measurement of the areas covered or by direct determination with a Sedgewick ocular grid. After $24 \mathrm{hr}$. of incubation, the aggregative centres or the fruits (one formed per aggregate) were counted under a $16 \mathrm{~mm}$. objective. To facilitate counting, the agar within the confines of each drop was lightly scored with a razor blade in a grid-like pattern; these marks served as guide lines.

Figure 1 summarizes the data obtained from three such experiments with three different population sizes, namely, 10,000, 5000, and 4000 cells. Other experiments not summarized here gave the same results. The number of centres per drop has been plotted against population density. Each point represents 
a mean of at least four replicate determinations. Table 1 presents numerical data bearing upon the number of centres formed at the optimal density.

Comparisons can be drawn at several points between the aggregative performance of the mutant and of the wild type (see the lower curve in Fig. 3 for reference). The most important difference lies in the capacity of the mutant to produce a great number of aggregates. Thus, at the optimal density, 10,000

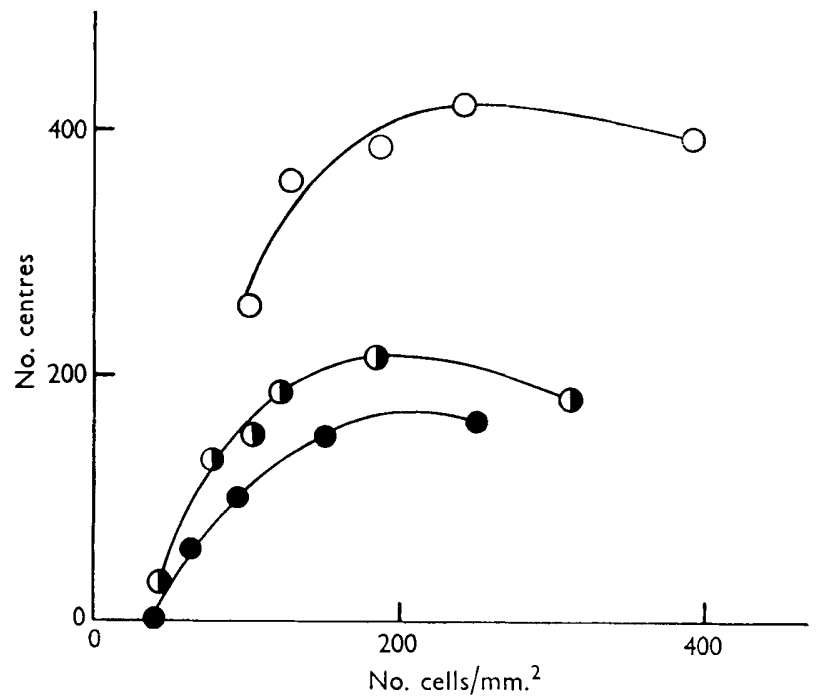

Fig. 1. The relation between centre formation and population density for Fty-1 on minimal agar. The ordinate refers to the number of centres formed/sample of 10,000 cells (upper curve $\bigcirc$ ), 5000 (middle curve, $\bigcirc$ ), and 4000 (lower curve, $\bullet$ ).

Table 1. The relation between the number of aggregative centres and the number of cells in Fty-1

$\begin{array}{cccc}\text { No. of cells } & \text { No. of centres } & \begin{array}{c}\text { Ratio: } \\ \text { centres : cells }\end{array} & \text { Optimal density } \\ 10,000 & 423 & 1: 24 & 240 \\ 6,000 & 250 & 1: 23 & 180 \\ 5,000 & 213 & 1: 24 & 200 \\ 4,000 & 168 & 1: 24 & 210\end{array}$

Washed Fruity cells were dispensed on minimal agar over a range of population densities. After incubation, counts were made of aggregative centres. Densities shown in the last column were those at which maximal centre formation occurred.

mutant cells produced 423 centres for a ratio of centres to cells of $1: 24$. In contrast, 10,000 wild type formed less than five centres representing a ratio of 1 : 2200 (Sussman \& Noel, 1952). Table 1 also indicates that at the optimal density the number of centres is in linear relation to the number of cells present, as is the case for the wild type.

The optimal densities for centre formation appear to be about the same for the two stocks. Similar decreases of the numbers of centres are observed at high population densities, although the mutant appears less sensitive in this 
respect. This is clearly seen in Fig. 2, where the percentage of maximal centre formation is plotted as a function of density; the curves have been fitted to data from many experiments. Note that at a density of $600 / \mathrm{mm} .{ }^{2}$, the wild type could form only $35 \%$ of the maximal number of centres, whereas the mutant could form $66 \%$. Also evident from this figure is the difference in sensitivity to the aggregative stimulus at low population densities. The aggregation of both stocks was impeded, but the wild type could not form any centres at densities below 80 cells $/ \mathrm{mm} .{ }^{2}$ while the threshold for Fty-1 was about 40 .

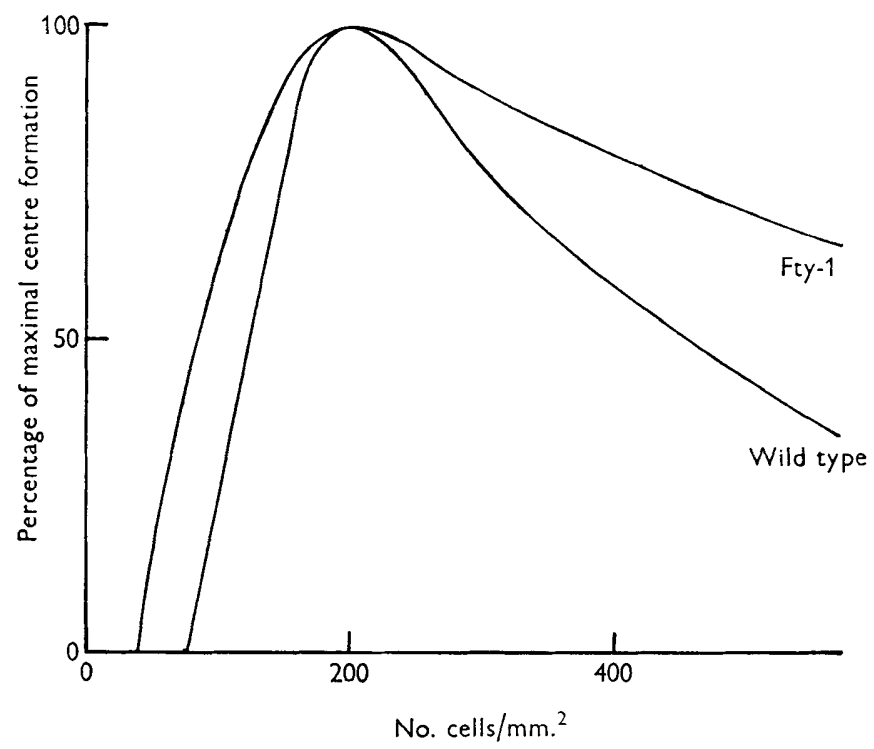

Fig. 2. Decrease of centre formation at low and high population densities.

The overall rate at which these stocks proceeded through the aggregative phase was about the same, with Fty-1 holding a slight advantage. In the mutant the first signs of impending aggregation occurred after 8-12 hr. of incubation, in the wild type after 12-16 hr.

\section{Aggregation by mixtures of wild type and Fty-1 cells}

A study of the mixed aggregations was carried out in order to determine whether wild-type responding cells could be affected by mutant initiators. The fact that they could, made it then possible to examine the following hypotheses. The capacity of the Fruity stock for augmented centre formation might be explained in at least two ways. The mutant myxamoebae might be presumed to be considerably more sensitive to the initiative stimulus than their wildtype counterparts, so much so that many putative initiator cells which, if faced with an audience of wild type responders would not be able to deliver a sufficiently strong stimulus to attract them, could do so in the presence of the hypersensitive mutants. Alternatively, one might imagine that the alteration 
had led to an increase in the proportion of myxamoebae which could act as initiators. In this case no special sensitivity need be ascribed to the mutant responder cells. To test these possibilities, cell mixtures containing very small numbers of mutant cells and very large numbers of wild-type cells were examined. In such a system, the majority of responder cells would be wild type, thereby uncoupling the mutant initiator/responder system.

The cells were grown, washed and suspended in salt solution. Mixtures were prepared and dispensed on minimal agar in different sized drops so that samples, each containing 10,000 wild type and 500 mutant cells, were dispersed over a range of population densities. Control suspensions of wild type only were similarly treated. After incubation, counts were made of the centres formed. Figure 3 shows the results of a typical experiment; the points represent

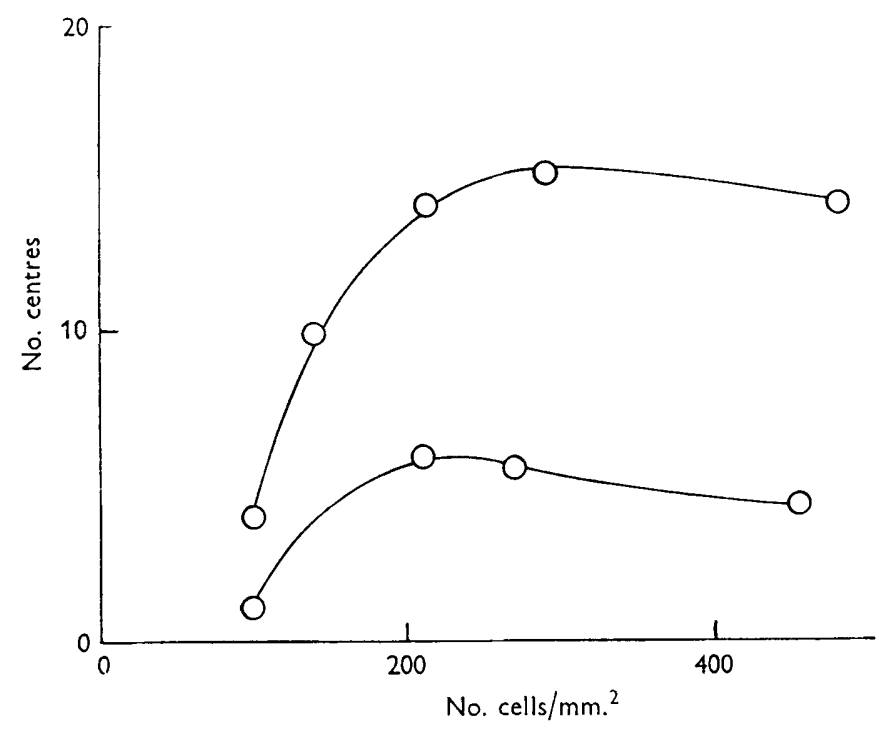

Fig. 3. The relation between centre formation and population density for Dictyostelium discoideum wild type (lower curve) and for a mixture of wild type and Fty-1 (upper curve).

averages of at least ten replicate samples. In all, six experiments were performed, involving nine different mixtures. Outside of the significant increase in number of centres formed, the experimental and control curves are quite comparable. The threshold of sensitivity at low population density appeared to be governed by the nature of the responding cells. In all of the experiments the lower limit was $c .80$ cells $/ \mathrm{mm}^{2}{ }^{2}$ rather than 40 which obtains when only mutant cells are present. The optimal population density was the same. The usual diminution of centre formation at densities above the optimal was apparent, though not as marked as in wild-type populations. Rather it was more like that observed with the mutant (see Fig. 2), suggesting that this diminution depended at least in part upon the nature of the initiator cells.

To determine the number of centres in the mixture due only to the presence of mutant initiator cells, the centres evoked by wild-type initiators at a given 
population density (obtained from the control curve) were subtracted from the total number of centres of the mixture. In this manner points were obtained for a new curve which related the number of centres evoked by the Fruity initiators to the population density of the mixture. Figure 4 shows two such curves; the data were obtained from four experiments with mixtures containing 1000 Fty-1 cells (upper curve) and 500 (lower curve). In each case a plateau was reached at a density approximating 300 cells $/ \mathrm{mm}^{2}$. Table 2 gives

Table 2. Centre formation by mixtures of wild type and Fty-1 cells

$\begin{array}{ccc}\text { No. of Fty-1 cells } & \begin{array}{c}\text { No. of centres } \\ \text { at plateau }\end{array} & \text { Ratio } \\ 1000 & 15 \cdot 8 & 1: 63 \\ & 15 \cdot 6 & 1: 64 \\ 750 & 11 \cdot 9 & 1: 63 \\ & 14 \cdot 6 & 1: 50 \\ 500 & 8 \cdot 8 & 1: 57 \\ & 9 \cdot 8 & 1: 51 \\ & \text { Mean } & 1: 58\end{array}$

The washed cells were mixed in varying proportions and dispensed over a range of population densities as described in the text. Values in the second column were derived from the curves shown in fig. 4 and from others not published. 'Ratio' in the last column refers to the ratio of centres evoked by mutant initiators to the number of mutant cells present.

Table 3. Centre: cell ratios for Fty-1 mixed with different numbers of wild type

$\begin{array}{cccc}\begin{array}{c}\text { No. of } \\ \text { Fty-1 cells }\end{array} & \text { Ratio } & \overbrace{\begin{array}{c}\text { No. of } \\ \text { Fty-1 cells }\end{array}}^{\text {Ratio }} \\ 1200 & 1: 59 & 1200 & 1: 61 \\ 1100 & 1: 56 & 1100 & 1: 59 \\ 1000 & 1: 62 & 1000 & 1: 60 \\ 900 & 1: 65 & 900 & 1: 63 \\ 800 & 1: 61 & 800 & 1: 60 \\ 700 & 1: 64 & 600 & 1: 58 \\ 600 & 1: 58 & & \\ 500 & 1: 62 & & \\ 400 & 1: 64 & \text { Mean } & 1: 60 \\ \text { Mean } & 1: 61 & & \end{array}$

See text for experimental details. The values given in column A were obtained from mixtures of the mutant with 10,000 wild type myxamoebae; those in column B with 25,000. The term 'Ratio' refers to the ratio of centres evoked by mutant initiators to mutant cells present in the mixtures.

the plateau values for three different numbers of mutant cells mixed with 10,000 wild type. The mean ratio of centres evoked by mutant initiators to mutant cells is seen to be $1: 58$. In another series of experiments, mixtures containing from 400 to 1200 mutant cells and 10,000 or 25,000 wild type were dispensed at densities around 400 cells $/ \mathrm{mm}^{2}$. Table 3 gives mean ratio values for the mutant, each representing at least four replicate determinations. The 
ratio is constant and appears to be independent of the number of wild type present or the state of dispersion of the mutant cells. The fact that the number of centres ascribed to the mutant is proportional to the number of Fruity cells (thus providing a constant ratio) and is independent of the state of dispersion of the Fruity cells in the mixture indicates that single mutant cells act to initiate the aggregative centres.

The plateaus that appear in Fig. 4 persist even at extremely high population densities. The results of one experiment with mixtures of 1000 mutant and 50,000 wild type showed that the usual ratio occurred even at a density of 1100 cells $/ \mathrm{mm}^{2}$ and only at 1800 was a significant diminution of centre formation observed.

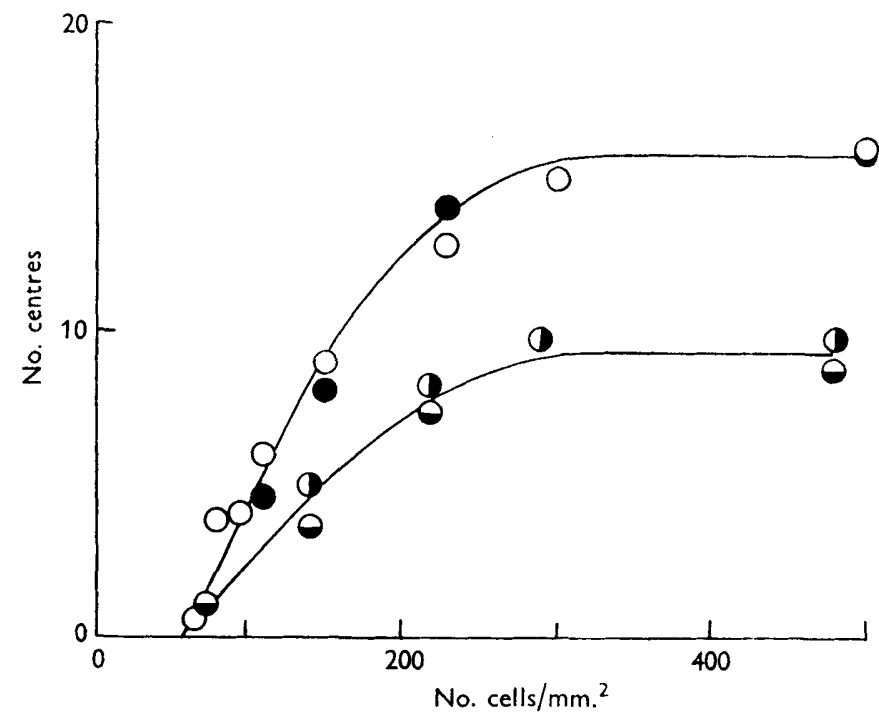

Fig. 4. The numbers of centres due to the presence of Fty-1 initiators in mixtures with wild type cells at different population densities. The upper curve was obtained for 1000 Fty-1 cells and the lower for $500 \mathrm{Fty}-1$ when mixed with 10,000 wild type. Two separate experiments were performed for each of the mixtures.

To return to the question raised at the beginning of this section, the foregoing indicates that almost as many centres are evoked by Fruity initiators in a test system composed of wild-type responder cells as in the presence of mutant responders. Thus, in the former system the ratio of mutant cells to centres evoked by mutant initiators was about $1: 60$ and in the latter system, $1: 24$. In contrast, the corresponding value for the wild type initiator/responder system is $1: \mathbf{2 2 0 0}$. It seems therefore that most of the enhanced centre producing capacity of the mutant can be ascribed to an increase in the proportion of initiator cells. Since, however, there is a significant difference (60 against 24) in the ratios obtained with the two test systems, at least a part of this capacity must involve enhanced sensitivity of the mutant responding cells to the initiative stimulus. 


\section{Microscopic observations of Fty-1 aggregation}

A population of wild type myxamoebae in the midst of aggregation is truly a remarkable sight. The process begins with greatly increased pseudopodial activity and sudden and drastic elongation of the cells. Active directed motion follows and, as the cells approach each other all travelling in roughly radial paths, the first dim outlines of the cell streams become apparent. With subsequent crowding the streams are clearly delineated and are fortified by the arrival of reinforcements. Major and minor branching occur at the distal ends. A sticky material appears to hold the streams together (Dr B. M. Shaffer, personal communication). The cells move toward the centre which rapidly emerges as a cone-shaped mass. At its peak, the aggregation figure may extend over a diameter of a few millimetres. By the time the last cells are nearing the centre, the aggregate has already taken on the distinctive outlines of the pseudoplasmodium. Depending on the population density, a few hundreds to many thousands of cells may be incorporated in a single aggregate. Photomicrographs of typical wild type aggregations have been published elsewhere (Raper, 1951; Raper \& Fennell, 1952).

In view of the drastic decrease in the numbers of cells normally entering the Fruity aggregates, it was of interest to examine the form that the mutant aggregate takes and the way in which the cells enter it. Plates 1 and 2 show a series of time-lapse still photomicrographs of Fty-1 myxamoebae during aggregation. The cells had been dispensed on minimal agar at a population density slightly greater than the optimal. A field was chosen at random and the Petri dish was taped rigidly to the microscope so that serial photographs could be taken. A $\times 10$ ocular and a $\times 10$ objective were used. The first photograph (fig. 1) was taken after $10 \mathrm{hr}$. of incubation, and the succeeding ones at $13,13 \cdot 5,15 \cdot 5$ and $24 \mathrm{hr}$. The times respectively involved should not be considered critically since the experiment was performed during a Chicago summer at ambient temperature very close to the upper allowable limit. Thus the time between the beginning of aggregation and fruiting body formation was greatly in excess of the norm. In all other respects the pattern was typical.

A number of features may be noted: (i) there was no evidence of cell elongation or stream formation; (ii) the aggregate remained amorphous even after a considerable number of cells had arrived at the centre and even the completed aggregate had not yet achieved the shape of a typical pseudoplasmodium; (iii) the cells appear to have been in constant random motion prior to their aggregation. It is impossible to follow the movement of more than a few cells even through two photographs.

Estimation of the number of cells which entered this aggregate can only be approximate. It is based on the number of cells in the field and the relative size of the aggregate; from this we estimate that less than 100 cells took part. Notice that in Pl. 2, fig. 5, the field was shifted slightly to include a second and smaller aggregate; probably less than 20 cells entered this one.

Of primary interest is the question of whether one might not be able to 
identify the initiator cell in a beginning aggregate, by some difference in morphology, motility or other property. The mutant aggregations would seem to be ideal material for a study of this kind because of the small number of cells involved; this is under investigation.

\section{The comparative anatomy of the mutant fruits}

Because of the small numbers of cells involved, it was of interest to examine the structure of the mutant fruiting body. Pls. 3 and 4 are photomicrographs of three examples. They were obtained by choosing a fruit whose axis was not perpendicular to the agar and allowing a drop of immersion oil to fall upon it. The oil served to press the fruit down upon the agar and to squeeze excess water from it and clarify the view. The photographs were taken with a bellowsequipped camera over a $\times 10$ ocular and $\times 90$ oil-immersion objective. Pl. 3, fig. 6 , is a montage since the fruit occupied two fields. The structure is relatively large and probably came from an aggregate of the same size as that shown in the previous figure. Microscopic examination at several focal planes revealed that the fruit contained about fifty spores, 4 to 6 stalk cells and probably 1 basal disk cell. Pl. 4, figs. 7 and 8 shows views in two focal planes of a smaller fruit containing 9 spores, 2 stalk cells, and probably 1 basal disk cell. Pl. 4, fig. 9 is of interest because of the sharp delineation of the stalk cells.

The results of morphological examination of these and a few other mutant fruits are outlined below. Where possible, comparisons have been drawn with the corresponding anatomical features of the wild type.

$S$ pores. The mutant spores appear indistinguishable from those of the wild type with respect to size, shape and cell-wall thickness. Measurement of the major and minor diameters of 30 mutant spores yielded averages of $7 \cdot 5$ and $4 \cdot 25 \mu$., or a mean of $5 \cdot 9 \mu$. Corresponding dimensions for the wild type were $7 \cdot 1$ and $4.5 \mu$, or a mean of $5 \cdot 8 \mu$. Bonner \& Frascella (1949), after a much more extensive study, found a mean of $6 \cdot 0 \mu$. for the wild type.

Stalk cells. As in the wild type (Raper, 1941 ; Raper \& Fennell, 1952), the mutant stalk cells are firm, thick walled and completely vacuolated. The latter property was made obvious in our examination by the presence of dancing bodies. As seen in these figures, the cells are singly tiered and vertically oriented. The dimensions of four clearly delineated cells ranged between $\mathbf{2 \cdot 6}$ and $3 \cdot 8 \mu$. in width and 28 and $32 \mu$. in length. Raper (1941) noted tiny wild type fruits formed at low population density whose stalk cells were similarly shaped with dimensions of $3.5 \times 15 \mu$. Raper's findings also indicated great plasticity of stalk cell shape since in slightly thicker stalks the cells became progressively more isodiametric.

At the other extreme are the stalks of relatively huge wild type fruits formed on growth plates at very high population density. These contain tiers of 10-15 cells all isodiametric (Raper, 1941). The same can be said of the mutant fruits formed under similar circumstances although none have been seen that are that thick.

In the wild type, the stalk cells are encased in a tubular tapered cellulose sheath (Raper \& Fennell, 1952). Sheaths were also observed by us in the 
mutant, although the nature of the material was not determined. In the tiny fruits of both varieties, the sheaths are not readily distinguishable from the outer cell walls.

Gross proportions of the fruits. Table 4 lists the lengths of six mutant fruits and the ratio of cells present to fruit length; the shortest was $45 \mu$. and the longest $190 \mu$. The mutant fruits on growth plates commonly attain a height of 1 or $2 \mathrm{~mm}$. In contrast, of the wild type fruits examined by Raper (1941), the smallest was $750 \mu$. and the largest $4500 \mu$. The ratio values in Table 4 indicate a constancy of gross proportions regardless of the number of cells present; this point requires more extensive study. Similar data for the wild type are not available. The ratio of the diameter of the spore mass to the length of the stalk was determined for fruits of very different sizes by Raper (1941), who found a constant ratio of 0.1 ; corresponding measurement of a limited number of mutant fruits yielded a constant value of $\mathbf{0 \cdot 2}$.

Table 4. The relation between the lengths of the mutant fruits and the numbers of cells comprising them

$\begin{array}{cccc}\text { Fruit } & \begin{array}{c}\text { No. of } \\ \text { cells }\end{array} & \begin{array}{c}\text { Fruit length } \\ (\mu .)\end{array} & \begin{array}{c}\text { Ratio, } \\ \text { cells : length }\end{array} \\ 1 & 12 & 70 & 0 \cdot 17 \\ 2 & 13 & 45 & 0 \cdot 29 \\ 3 & 15 & 66 & 0 \cdot 23 \\ 4 & 19 & 99 & 0 \cdot 19 \\ 5 & 32 & 125 & 0 \cdot 25 \\ 6 & 56 & 190 & 0 \cdot 29\end{array}$

Ratio of spores and stalk cells. On the basis of limited data, the ratio of stalk cells to spores in the mutant was found to be relatively constant despite differences in absolute numbers and to range between $0 \cdot 1$ and $0 \cdot 2$. Bonner $\&$ Slifkin (1949), in an extensive study of the parental strain under slightly different environmental conditions, found a ratio of $0 \cdot 14$.

From the foregoing, it would appear, that aside from considerations of absolute size, the mutant fruits do not differ from those of the wild type to any significant extent. This implies that the processes which in the parental variety determine the morphology of the fruit, both macro-and microscopic, proceed normally within the mutant unaffected by the genetic alteration. The capacity of these organisms for developmental regulation (i.e. constancy of morphogenetic properties regardless of the absolute size of the cell assembly) should be noted. From fruits measured in millimetres and containing many thousands of cells to fruits measured in microns and containing relatively few cells, the gross and microscopic aspects are preserved intact.

\section{The regulatory properties of the fruiting process}

As shown by Raper (1941) and by Bonner \& Slifkin (1949), the fruit of Dictyostelium discoideum maintains a constancy of gross form, proportions and histological features whether it be composed of hundreds of cells or of many thousands. Now the fruity mutant has extended this regulatory scale down- 
ward to include structures composed of as few as 12 cells and perhaps less. One may ask the question as to what in a developing population of myxamoebae determines whether a given individual is to become a spore, stalk, or basal disk cell and further, what determines the proportions of the types within the differentiated assembly. A partial answer has been gained through studies (Raper, 1940; Bonner, 1944) which indicate that the fate of a cell in these regards is governed by its relative position in the aggregate and pseudoplasmodium. Experimentally contrived changes of position result in predictable alterations of that fate. This suggests that the differentiation of the myxamoebae is mediated by cell/cell interactions and that the proportions of the various cell types represent resultants among the matrix of interactions. Study of synergistic development by paired combinations of morphogeneticallydeficient mutant strains (Sussman, 1954) has provided strong support for this concept and the additional information (Sussman \& Lee, 1955) that in those synergistic relations examined, the material exchanged between the partners is not diffusible but rather is passed by direct cell contact. The pertinence of the Fruity mutant to the problem lies in the small numbers of cells that take part in the organization. If 9 pre-spore cells can regulate the transformation of 2 pre-stalk cells or vice versa, then the interactions attending the transformations must be extremely powerful in the sense that they need not be actions to which many cells contribute. Rather must it be that the control proceeds through direct effects of one or at most a few cells upon another, with perhaps the additional requirement of correct geometric orientation of effector and effectee. It would seem that the Fruity mutant may provide the means for a delicate attack upon this problem.

In addition, it has been observed that extracts or washings of the Fruity myxamoebae, when incorporated into the minimal agar, induce the wild type to form phenocopies of the mutant aggregations and fruits. Our best preparations have provided more than a tenfold increase in the expected number of aggregative centres. This increase does not result from growth of the wild type cells on the plates or the presence of viable mutant cells in the extracts or washings. The enhanced aggregative capacity is not maintained by progeny of spores taken from the experimental plates. The chemical and biological features of this phenomenon are currently being studied.

\section{The dwarf mutant of Dictyostelium discoideum}

Some time after the investigation of Fty-1 had been started, it was recalled that a mutant Dwarf Dw-1, isolated 2 years previously, resembled the Fruity mutant in many respects. At the time of its isolation the small size of the fruits of Dw-1 rather than the increase in their number held our attention since we then possessed no preconceptions regarding genetically determined increases in the number of initiator cells. Re-examination of $\mathrm{Dw}-1$ has revealed that it too is a 'fruity' stock although not as extreme in this respect as Fty-1. A study of aggregative performance on minimal agar revealed that the response of Dw-1 to population density changes was about the same as that of Fty-1, but that the ratio of centres to cells of the former is $1: 40$ as against $1: 24$ for the 
latter. The fact that the two mutants show slightly different characteristics indicates that initiative capacity in Dictyostelium discoideum is controlled by a multiplicity of genetic determinants.

Aggregation of the Bushy mutant of Dictyostelium discoideum

Another mutant designated NC-4 bu, was isolated some time ago and its overall morphogenetic pattern described (Sussman \& Sussman, 1953). The myxamoebae of NC-4 bu appear to aggregate in normal fashion. The mutant aggregate is not, however, transformed into the usual pseudoplasmodium, but instead remains stationary and upright and becomes heavily papillated. From each papilla emerges a tiny fruiting body with spore mass and stalk. An

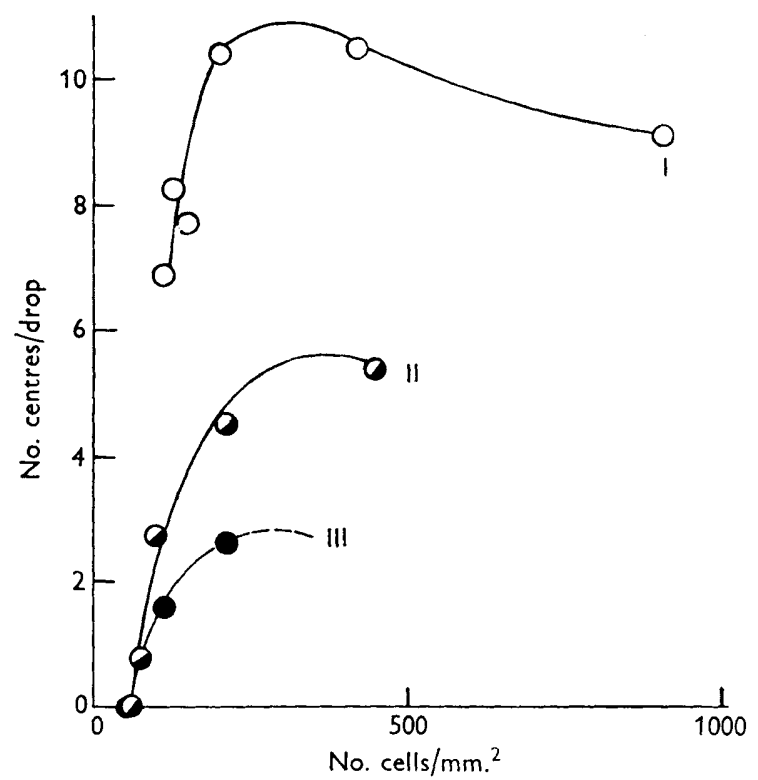

Fig. 5. The relation between centre formation and population density for the mutant, Bu-1. Curve I was obtained with aliquots of 20,000 cells, $O$; curve II with 10,000 , $O$; and curve III, with 5000

analysis of the aggregation of this mutant was performed by the procedure previously described. Figure 5 shows the relation between centre formation and population density. Curve I was obtained with populations of $2 \times 10^{4}$ cells, curve II with $1 \times 10^{4}$ cells, and curve III with $5 \times 10^{3}$. As with the wild type, no centres were formed by the Bushy cells at very low population densities (c. 70 cells $/ \mathrm{mm}^{2}$ ); at very high densities the number of centres was depressed by interactions between the closely apposed potential centre-forming agencies. At an intermediate density a maximal number of centres was produced, proportional to the number of cells present. Table 5 is a numerical summary of these results. The mean ratio of centres : cells for the Bushy strain was about $1: 1800$, to be compared with the $1: 2200$ ratio for the wild type. In view of 
Table 5. Centre formation by the Bushy mutant at optimal population density

$\begin{array}{ccc}\text { No. of cells } & \text { No. of centres } & \text { Ratio } \\ 20,000 & 10 \cdot 9 & 1: 1830 \\ 10,000 & 5 \cdot 5 & 1: 1820 \\ 5,000 & 2 \cdot 8 & 1: 1780 \\ & \text { Mean } & 1: 1810\end{array}$

the random sampling error inherent in this technique, the difference may not be significant. However, the optimal population density for Bushy (about 350 cells $/ \mathrm{mm}^{2}$ ) does differ significantly from the corresponding value for the wild type ( 200 cells $\left./ \mathrm{mm}^{2}\right)$. In addition, a difference was observed in the rates of development. All wild type aggregates appear well before $24 \mathrm{hr}$. of incubation on washed agar. Aggregates of Bushy cells continued to appear until $48 \mathrm{hr}$. of incubation. At high population densities single Bushy aggregates produced multiple fruiting structures, as many as four or five fruits arising therefrom. At low densities where each aggregate contained fewer cells only single fruits appeared.

This work was performed with the aid of funds supplied by the Office of Naval Research under contract NR 135-231 and by the National Institutes of Health, Public Health Service.

\section{REFERENCES}

Bonner, J. T. (1944). A descriptive study of the development of the slime mold D. discoideum. Amer. J. Bot. 31, 175.

Bonner, J. T. (1947). Evidence for the formation of cell aggregates by chemotaxis in the development of the slime mold $D$. discoideum. J. exp. Zool. 106, 1.

Bonner, J. T. (1949). Demonstration of acrasin in the later stages of development of the slime mold D. discoideum. J. exp. Zool. 110, 259.

Bonner, J. T. \& Frascella, E. B. (1949). Variations in cell size during development of the slime mold D. discoideum. Biol. Bull., Woods Hole, 104, 297.

Bonner, J. T. \& SuIfkin, M. (1949). Study of the control of differentiation : proportions of spore and stalk cells in the slime mold D. discoideum. Amer. J. Bot. 36, 727.

Bradley, S. G. \& Sussman, M. (1954). Physiology of aggregation during the development of the slime mold $D$. discoideum. Bact. Proc. p. 32.

RAPER, K. B. (1940). The communal nature of the fruiting process in the Acrasieae. Amer. J. Bot. $27,436$.

RAPER, K. B. (1941). Developmental patterns in simple slime molds. Groreth, 5, 41.

RAPER, K. B. (1951). Isolation, cultivation and conservation of simple slime molds. Quart. Rev. Biol. 26, 169.

Raper, K. B. \& Fennell, D. (1952). Stalk formation in Dictyostelium. Bull. Torrey bot. Cl. 79, 25.

RAPER, K. B. \& Thом, C. (1941). Interspecific mixtures in the Dictyosteliaceae. Amer. J. Bot. 28, 69.

Runyon, E. H. (1942). Aggregation of separate cells of Dictyostelium to form a multicellular body. Collect. Net, 17, 88.

Shaffer, B. M. (1953). Aggregation in cellular slime molds: in vitro isolation of acrasin. Nature, Lond., 171, 975. 
Journal of General Microbiology, Vol. 13, No. 2

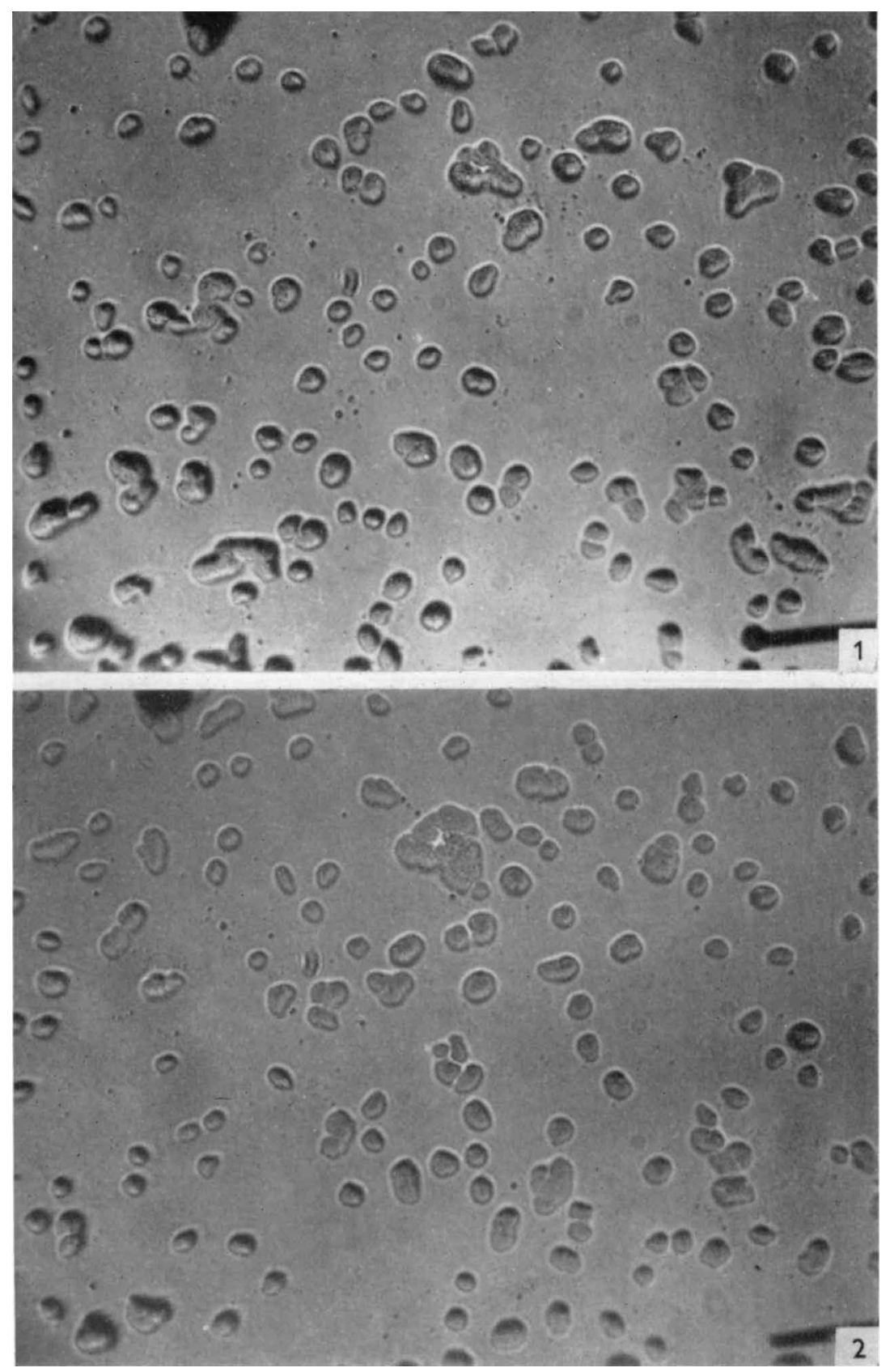

M. Sussman-Mutants of Dhetgostellem hocoldely. Plate 1

(Fucing $p .308)$ 
Journal of General Microbiology, Vol. 13, No. 2
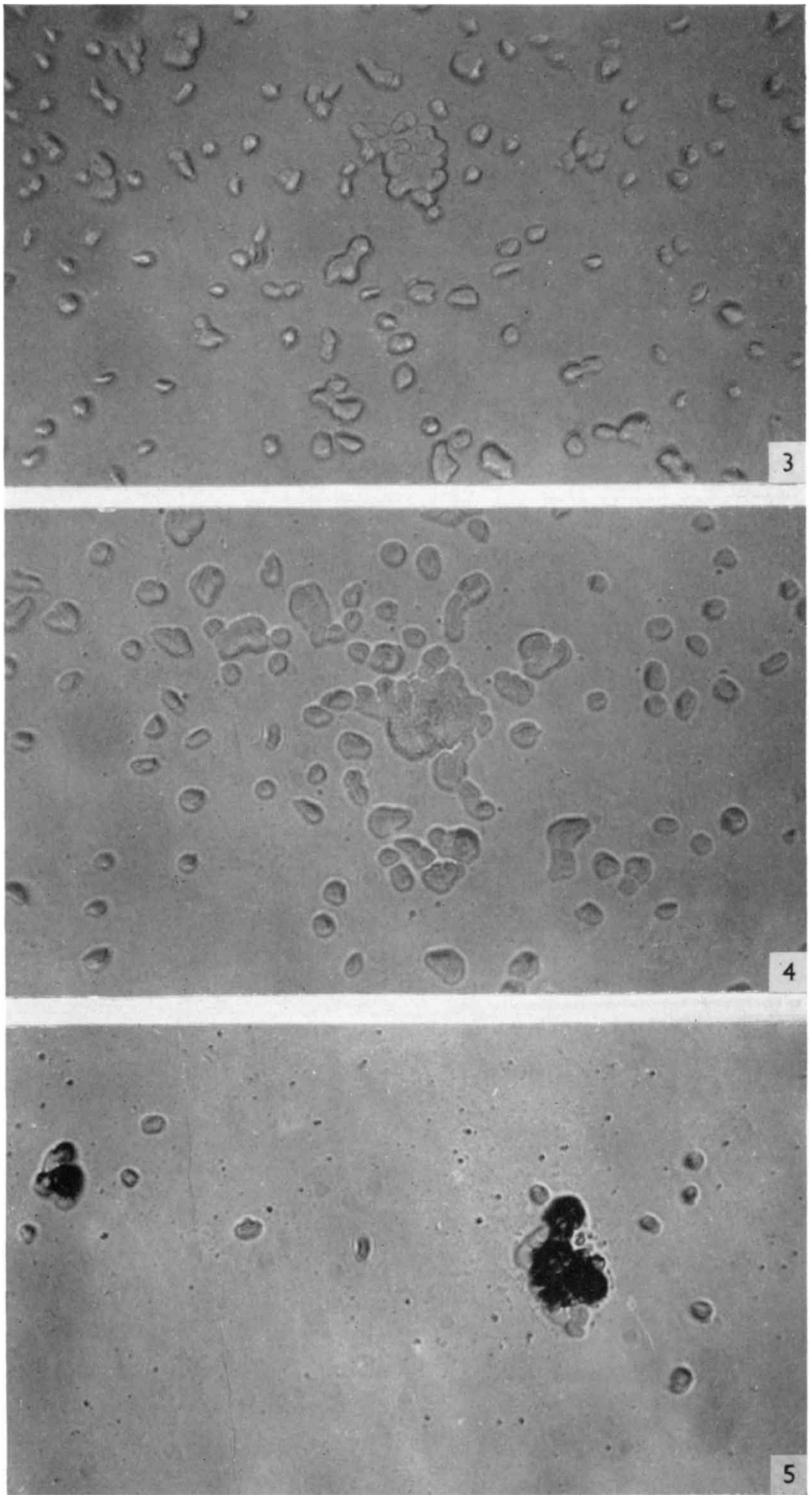

M. Sussman-Mutants of Dictyosteliem discoldeum. Plate 2 
Journal of General Microbiology, Vol. 13, No. 2

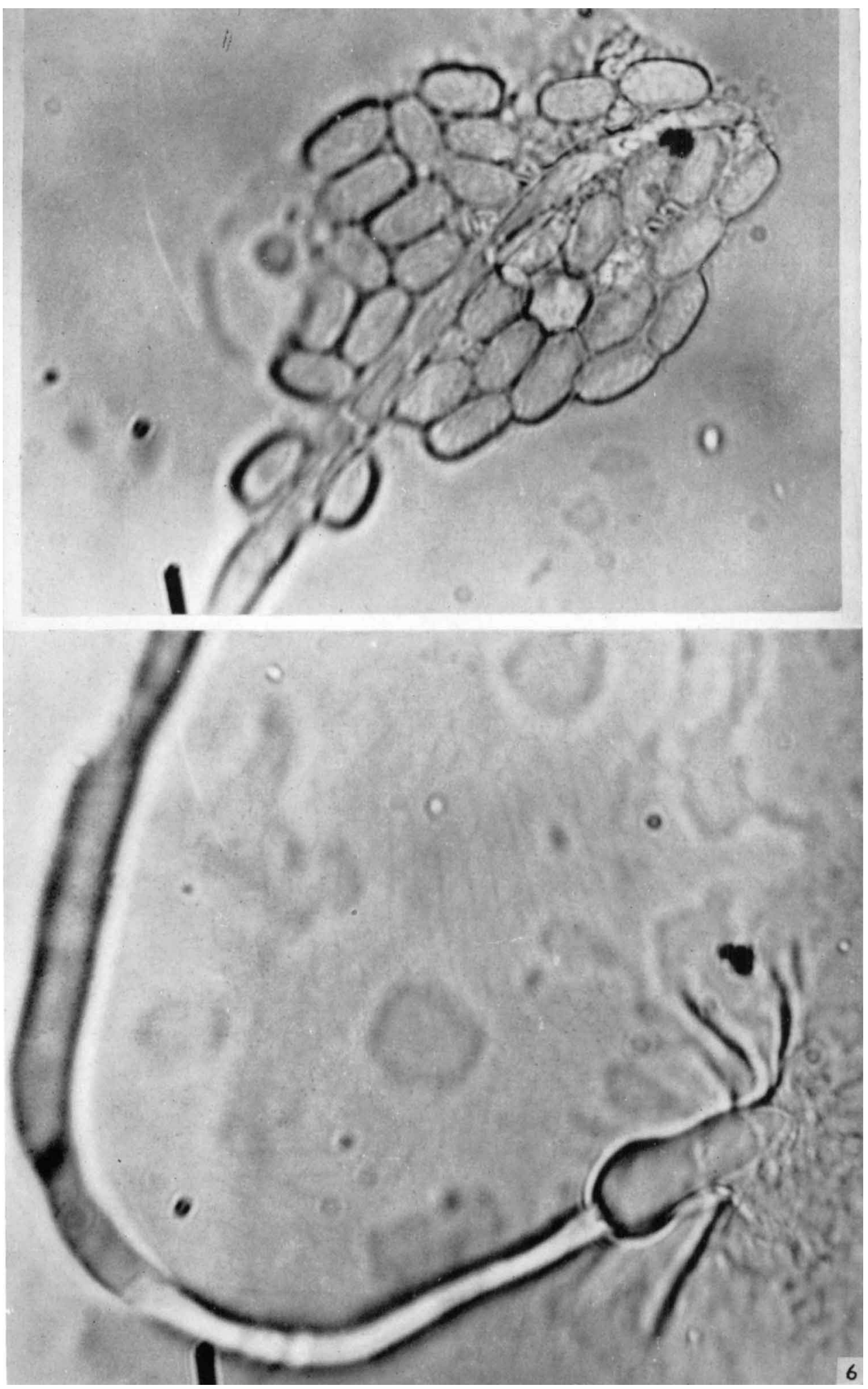

M. Sussman-Mutants of Dictyostelium discoidevin. Plate 3 
Journal of General Microbiology, Vol. 13, No. 2
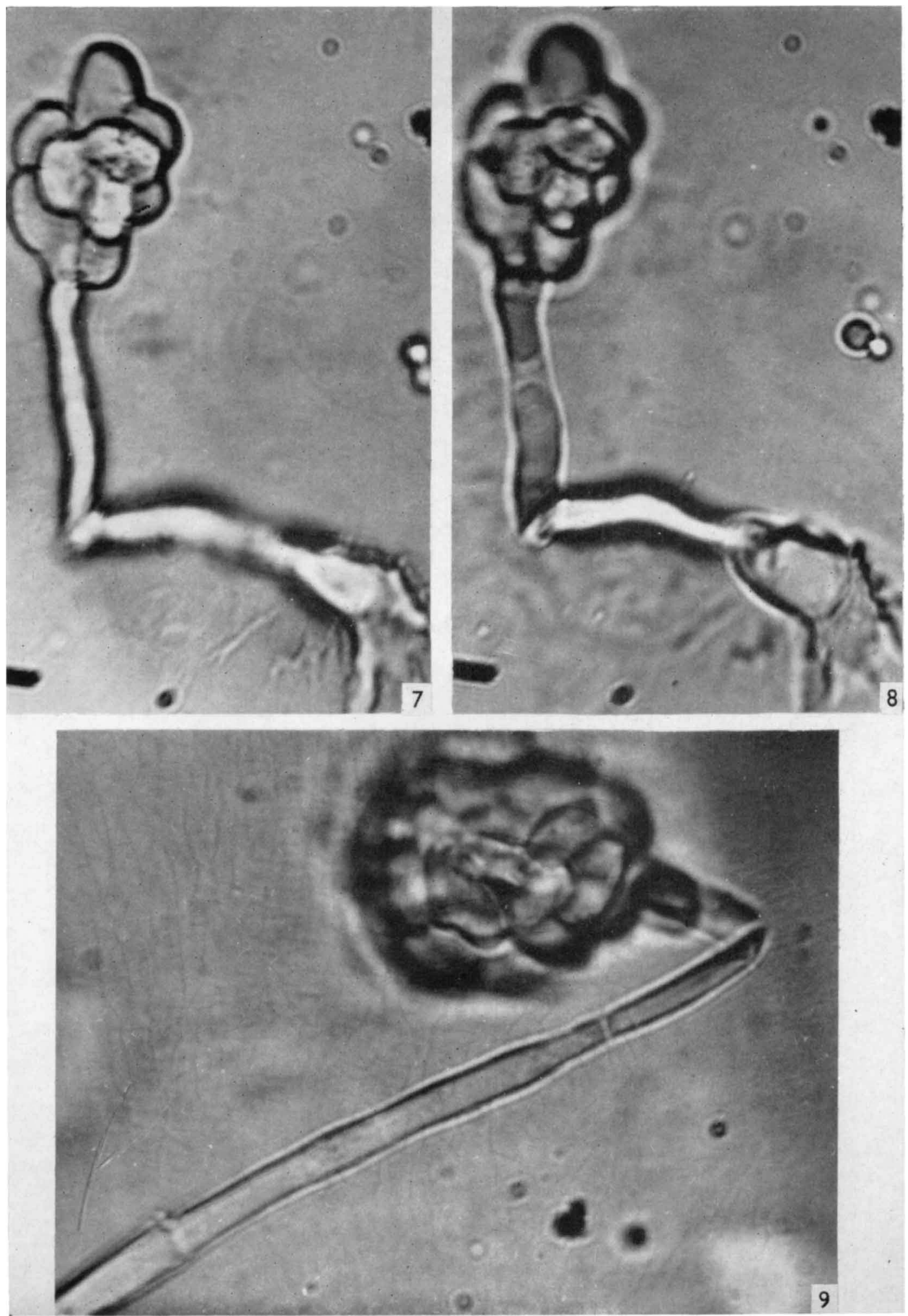

M. Sussman-Mutants of Dictrostelium discoldeum. Plate 4 
Sussman, M. (1951). Origin of cellular heterogeneity in the slime molds. J. exp. Zool. 118, 407.

Sussman, M. (1952). Analysis of the aggregation stage in the development of the slime molds, Dictyosteliaceae. II. Aggregative centre formation by mixtures of D. discoideum wild type and aggregateless variants. Biol. Bull., Woods Hole, $193,446$.

Sussman, M. (1954). Synergistic and antagonistic interactions between morphogenetically deficient variants of the slime mold, D. discoideum. J.gen. Microbiol. $10,110$.

Sussman, M. (1955). The developmental physiology of the cellular slime molds, in Biochemistry and Physiology of Protozoa, vol. 2, ed. Lwoff, A. \& Hutner, S. H. New York: Acad. Press.

Sussman, M. \& Lee, F. (1954). The physiology of developmental variants among the cellular slime molds. Bact. Proc. p. 42.

Sussman, M. \& LeE, F. (1955). Interactions among variant and wild type strains of cellular slime molds across thin agar membranes. Proc. nat. Acad. Sci., Wash. 41 .

Sussman, M. \& Noel, E. (1952). Analysis of the aggregation stage in the development of the slime molds, Dictyosteliaceae. I. Populational distribution of the capacity to initiate aggregation. Biol. Bull., Woods Hole, 103, 259.

Sussman, R. R. \& Sussman, M. (1953). Cellular differentiation in Dictyosteliaceae: heritable modifications of the developmental pattern. Ann. N.Y. Acad. Sci. 56, 949, Art. 5.

\section{EXPLANATION OF PLATES}

\section{Plate 1}

Figs. 1, 2. Serial photomicrographs of an Fty-1 aggregation. Fig. 1 (upper) was taken after $10 \mathrm{hr}$. of incubation on minimal agar; the lower photograph (fig. 2) after $13 \mathrm{hr}$. Magnification, $\times 300$.

\section{Plate 2}

Figs. 3-5. Serial photomicrographs of an Fty-1 aggregation. Fig. 3 (upper) was taken after $13.5 \mathrm{hr}$. incubation on minimal agar; fig. 4 (middle) after $15.5 \mathrm{hr}$; ; fig. 5 (lower) after 24 hr. Magnification $\times 300$.

\section{Plate 3}

Fig. 6. A photomicrograph of a mutant fruit in situ. This is a montage of two fields. Magnification $\times 1650$.

\section{Plate 4}

Figs. 7-9. Figs. 7, 8 (upper left and right). Photomicrographs in two focal planes of a mutant fruit in situ. Magnification $\times 1760$. Fig. 9. Photomicrograph showing a stalk cell of a mutant fruit. Magnification $\times 1760$. 